\title{
Lodo de estação de tratamento de água como componente para germinação de mudas florestais
}

As Estações de Tratamento de Água transformam a água bruta em água potável retirando as partículas indesejáveis através de processos físicos e químicos, gerando um lodo que pode ser altamente tóxico, com destinação incompatível com as diretrizes da Lei 12.305/2010, que prioriza a possibilidade de redução, reuso e reciclagem. Assim, o presente trabalho teve como objetivo avaliar as os atributos químicos do lodo de ETA e o seu potencial na germinação de sementes de Handroanthus impetiginosus (Mart. Ex) Mattos e de Eucalyptus camaldulensis Dehnh sob diferentes concentrações no substrato. O experimento foi conduzido em casa de vegetação na Universidade Federal de Rondônia, município de Rolim de Moura/RO no período de dezembro de 2018 a fevereiro de 2019. As características físico-químicas do lodo foram avaliadas por empresa particular e o cultivo das espécies das espécies de ipê e eucalipto foi realizado em bandejas de polietileno drenadas com concentrações crescentes de lodo de ETA de $0 \% ; 15 \% ; 30 \% ; 45 \%$ e $60 \%$ completadas com proporções iguais de solo + areia grossa. O delineamento experimental utilizado foi em blocos casualizados, com cinco tratamentos e quatro repetições cada. Diariamente, foi avaliada a porcentagem de germinação (G\%) e após a estabilização da germinação, foram calculados o índice de velocidade de germinação (IVG), tempo médio de germinação (TMG) e velocidade média de germinação (VMG) das sementes. O lodo mostrou-se rico em nutrientes e matéria orgânica, o que pode contribuir com a aeração e retenção de água no substrato, favorecendo a germinação das sementes. Em todos os tratamentos com $\mathrm{H}$. impetiginosus, houve germinação das sementes variando de 12,5\% a 90,18\%, onde as melhores porcentagens de germinação ocorreram nos tratamentos de maiores concentração de lodo de ETA. Considerando as médias de germinação de sementes, houve diferença significativa no tratamento com $45 \%$ de lodo que apresentou os melhores resultados (G\% = $90,18 \%$; IVG 42,15: TMG $=4,40$ : VMG $=0,224$ sementes dias-1). Em relaça 0 a E. camaldulensis, também houve germinacão em todos os tratamentos, variando de $10,71 \%$ a $43,75 \%$. Sendo a melhor por porcentagem de germinação o tratamento com $15 \%$ de lodo $(\mathrm{G} \%=34,8 \%)$ e o tratamento T4 apresentou os melhores valores de IVG $(9,32)$, TMG $(4,72)$ e VMG $(0,212$ sementes.dias-1). 0 concentrações de até $45 \%$ de lodo de ETA incorporado a solo e areia.

Palavras-chave: Ipê; Eucalipto; Germinação; Amazônia; Fitorremediação.

\section{Water treatment station body as a component for forestry management}

\begin{abstract}
Water Treatment Plants turn raw water into drinking water by removing unwanted particles through physical and chemical processes, generating sludge that can be highly toxic, with disposal incompatible with the guidelines of Law 12.305 / 2010, which prioritizes the possibility of reduction, reuse and recycling. Thus, the present work aimed to evaluate the chemical attributes of ETA sludge and its potential in the germination of seeds of Handroanthus impetiginosus (Mart. Ex) Mattos and Eucalyptus camaldulensis Dehnh under different substrate concentrations. The experiment was carried out in a greenhouse at the Federal University of Rondônia, Rolim de Moura / RO, from December 2018 to February 2019. The physicochemical characteristics of the sludge were evaluated by a private company and the cultivation of the species of the ipê and eucalyptus species were carried out in drained polyethylene trays with increasing concentration of 0\% ETA sludge; $15 \% ; 30 \% ; 45 \%$ and $60 \%$ completed with equal proportions of soil + coarse sand. The experimental design was randomized blocks with five treatments and four replications each. The germination percentage (G\%) was evaluated daily and after germination stabilization, the germination speed index (IVG), the average germination time (TMG) and the average germination speed (VMG) of the seeds were calculated. The sludge was rich in nutrients and organic matter, which may contribute to aeration and water retention in the substrate, favorin gern armil seed gerion with higher concentration of $(G \%=90.18 \% ; \mathrm{IVG}=42.15 ; \mathrm{GMT}=4.40 ; \mathrm{VMG}=0.224$ seeds.days). -1$)$. Regarding $\mathrm{E}$. camaldulensis, there was also germination in all treatments, ranging from $10.71 \%$ to $43.75 \%$. Being the best germination percentage the treatment with $15 \%$ sludge $(G \%=34.8 \%)$ and the T4 treatment presented the best values of IVG $(9,32)$, TMG $(4,72)$ and VMG $(0,212$ seeds. days-1). ETA sludge presents high concentrations of organic matter, macro and micronutrient, so it can contribute to seedling germination and growth if used in concentrations of up to $45 \%$ of ETA sludge incorporated into soil and sand.
\end{abstract}

Keywords: Ipê; Eucalyptus; Germination; Amazon; Phytoremediation.

Topic: Ciências Florestais

Reviewed anonymously in the process of blind peer.

Geremias Dourado da Cunha (D)

Universidade Federal de Rondônia, Brasil

http://lattes.cnpq.br/1897564799872972

http://orcid.org/0000-0002-3172-5536

geremiasdarwin@gmail.com

\section{Rosalvo Stachiw (iD)}

Universidade Federal de Rondônia, Brasil

http://lattes.cnpq.br/1646641940410936

http://orcid.org/0000-0001-6901-3852

rosalvo.stachiw@gmail.com

Kenia Michele de Quadros (iD)

Universidade Federal de Rondônia, Brasil

http://lattes.cnpq.br/2209314957208420

http://orcid.org/0000-0003-0873-9582

keniamicheletronco@gmail.com

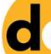

DOI: 10.6008/CBPC2179-6858.2020.001.0005
Received: $15 / 12 / 2019$

Approved: 15/01/2020
Referencing this:

CUNHA, G. D.; STACHIW, R.; QUADROS, K. M.. Lodo de estação de tratamento de água como componente para germinação de mudas florestais. Revista Ibero Americana de Ciências Ambientais, v.11, n.1, p.40-53, 2020. DOI: http://doi.org/10.6008/CBPC2179$\underline{6858.2020 .001 .0005}$ 


\section{INTRODUÇÃO}

O sistema de saneamento básico é formado por um conjunto de ações que visa melhorar e proteger as condições de vida da população. E uma destas ações é permitir que a população tenha acesso ao abastecimento de água potável por meio das Estações de Tratamento de Água (ETA's). Sendo assim, as ETA's removem as impurezas da água, por meio de processos de coagulação, floculação, decantação e filtração, e gera um resíduo nos decantadores e filtros chamado de lodo de ETA. Sua composição é bem diversificada, contendo diversos metais e podendo variar de acordo com o tipo de coagulante e produtos auxiliares utilizados no tratamento da água. Devido a sua composição química, trata-se de um resíduo sólido não inerte que necessita de uma destinação final adequada.

Muitas vezes, esse lodo gerado é depositado diretamente nos corpos d'agua, causando grande impacto ao ecossistema devido aos componentes presentes nele. Entretanto, este resíduo é classificado pela NR10004/2004 como um resíduo sólido de Classe II, não tóxico e não inerte. Logo, deve seguir as diretrizes da Política Nacional dos Resíduos Sólidos para destinação final, priorizando a não geração, redução, reutilização e ao tratamento dos resíduos sólidos, bem como a destinação dos rejeitos (BRASIL, 2010).

Sendo assim, é fundamental buscar alternativas economicamente viáveis e ambientalmente aceitáveis para destinação deste resíduo. Devido à elevada concentração de matéria orgânica, macronutrientes e micronutrientes, este resíduo pode contribuir para melhoria estrutural do solo como ajuste de pH, aumento da retenção hídrica e aumento da aeração do solo (TSUTUYA et al., 2001; MACHADO et al., 2004). Desta forma, uma alternativa viável de uso para o lodo de ETA é a utilização na produção de mudas de espécies florestais, tendo em vista que o mesmo apresenta elementos essenciais ao crescimento e desenvolvimento de vegetais (MACHADO, 2004).

A possibilidade de converter o lodo ETA em substrato para produção de mudas florestais para paisagismo, florestamento ou reflorestamento, pode ser uma forma de incentivar viveiristas e sistema público a criar parcerias que contribua com a redução do desmatamento em Rondônia que até o ano de 2017 teve $43,04 \%$ de suas florestas desmatadas, o que representou 28,5\% de desflorestamento na Amazônia Legal. Entre agosto de 2017 e julho de 2018, Rondônia contribuiu com 16,7\% dos $7.900 \mathrm{Km}^{2}$ de degradação florestal na referida região, posicionando-se como o terceiro estado com maior índice de desmatamento neste período (INPE, 2017; BRASIL, 2018a).

O gênero Handroanthus possui grande potencial germinador em ambientes tóxicos e por isso é indicado para programas de fitorremediação de solos contaminados. Inclusive seu potencial de fitorremediação para a germinação e crescimento em lodo de esgoto já foi constatado (ROCHA, 2018). Além disso, o gênero Handroanthus possui grande potencial paisagístico e madeireiro (LORENZI et al., 2003; SILVA et al., 2018). A madeira do Handroanthus quando serrada pode custar $\mathrm{R} \$ 2.025,00$ (dois mil e vinte cinco reais) e a madeira em tora tem custo de $\mathrm{R} \$ 1.800,00$ (mil e oitocentos reais) o metro cúbico. Esta ainda apresenta alta resistência mecânica ao ataque de insetos e ao apodrecimento, tendo grande relevância na produção de móveis (CAMPOS FILHO et al., 2015; BRASIL, 2018b). 
O gênero Eucalyptus também possui elevada relevância econômica devido ao seu rápido crescimento, capacidade de adaptação a diferentes ambientes e possiblidade de atender aos diversos setores da atividade industrial madeireira. O rápido crescimento natural das plantas do gênero Eucalyptus, associado à alta adaptação dos plantios clonais de diferentes gêneros, tem permitido a atividade florestal em todas as regiões do país, inclusive no estado de Rondônia que é ainda incipiente. Porém, devido à expansão das áreas de grãos no Cone Sul do estado, o município de Vilhena vem ampliando o cultivo desta espécie arbórea como alternativa de lenha para os secadores de grãos ali instalados. Dentre as espécies utilizadas, o Eucalyptus camaldulensis é frequentemente indicado em locais com condições de estresse hídrico e alta temperatura (PRADO et al., 2017).

A utilização da espécie de eucalipto em áreas de contaminação com metais tóxicos é uma das alternativas de grande potencial de fitorremediação em virtude do rápido crescimento, sistema radicular bastante desenvolvido e facilidade de aclimatação. Assim, as espécies de eucalipto podem minimizar os danos ambientais que o excesso de metais pesados causa, proporcionar retorno econômico e melhorias de áreas degradada.

Considerando que estas espécies possuem grande significado e alto potencial econômico, a produção de mudas dessas espécies utilizando o lodo de ETA como substrato é uma alternativa economicamente viável e ambientalmente adequada. Portanto, o objetivo deste trabalho é caracterizar os principais atributos físicoquímicos do lodo de ETA e avaliar a melhor porcentagem deste resíduo para ser utilizado como componente na germinação de Handroathus impetiginosus (Mart. ex DC) Mattos e Eucalyptus camaldulensis Denhn.

\section{MATERIAIS E MÉTODOS}

O experimento foi realizado de dezembro de 2018 a março de 2019 em casa de vegetação (dimensões de $6 \mathrm{~m} \times 9 \mathrm{~m} \times 3 \mathrm{~m}$ ), sob sombreamento de polietileno a $50 \%$ de permeabilidade aos raios solares, localizada nas dependências da Universidade Federal de Rondônia Campus Rolim de Moura/RO (1142'18.28"S e 6146'38.14"O). A região possui clima Am (Monção), com precipitação média anual de $2.250 \mathrm{~mm}$, umidade relativa do ar entre 80 e $90 \%$ e temperaturas médias anuais de $26^{\circ} \mathrm{C}$. $\mathrm{O}$ lodo utilizado foi coletado no mês de outubro de 2018, no início das chuvas na Estação de Tratamento de Água - ETA - de Porto Velho-RO (Figura 1), com captação de água no rio Madeira (8ะ47'22.79”S e 635'02.29"O), diretamente dos tanques de decantação, onde se acumula o lodo.

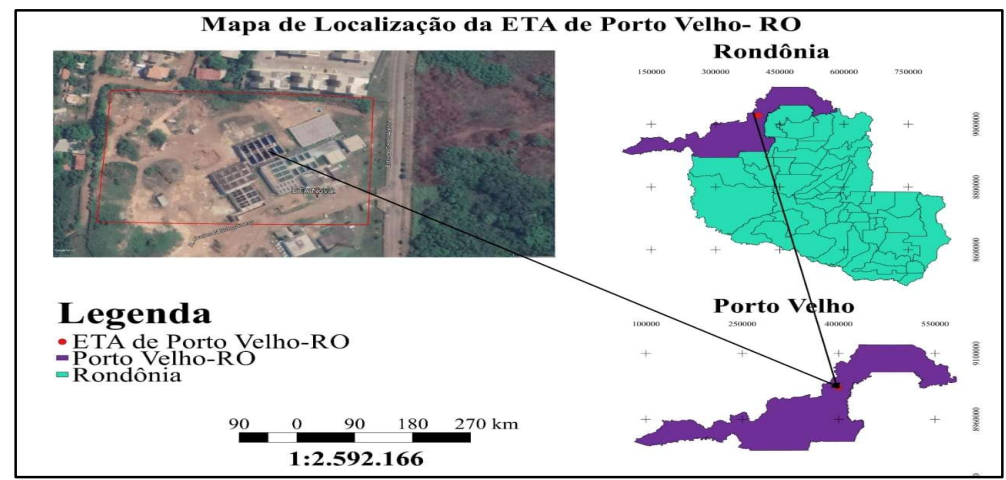

Figura 1: Localização da Estação de Tratamento de Água da Companhia de Água e Esgoto de Porto Velho/RO. 
Cerca de 200 kg de lodo foram coletadas e levada até o Laboratório de Recuperação de Ecossistemas e Produção Florestal - REProFlor - no Campus da Unir de Rolim de Moura. Então, foi retirada uma amostra de 2,0 kg do lodo, a qual foi seca em estufa a temperatura média de $60^{\circ} \mathrm{C}$ por um período de 12 horas e enviada para análise quali-quantitativa dos compostos, conforme os parâmetros estabelecidos na Resolução CONAMA no 375, de 29 de agosto de 2006 e Resolução CONAMA no. 430 de 13 de maio de 2011. Os atributos avaliados na massa seca do lodo foram: alumínio (Al), arsênio total (As), boro total (Bo), cádmio total (Cd), cálcio $(\mathrm{Ca})$, cobaldo $(\mathrm{Co})$, chumbo total $(\mathrm{Pb})$, ferro total $(\mathrm{Fe})$, manganês $(\mathrm{Mn})$, mercúrio total $(\mathrm{Hg})$, magnésio total $(\mathrm{Mg})$, níquel total $(\mathrm{Ni})$, potássio total $(\mathrm{K})$, berílio total $(\mathrm{Be})$, lítio total $(\mathrm{Li})$, fósforo total $(\mathrm{P})$, selênio total (Se), sódio total $(\mathrm{Na})$, zinco total $(\mathrm{Zn})$, matéria orgânica $(\mathrm{MO})$ e pH. Os metais potencialmente tóxicos e os metais ferro e manganês foram determinados pelas leituras feitas no Espectrômetro de Emissão Óptica com Plasma Indutivamente Acoplado (ICP-OES), seguindo as determinações da Standard Methods for Examination of Water and Wastewater (APHA, 2017). O restante do lodo coletado foi espalhado sobre uma lona preta e então solarizada durante 32 horas, sendo 8 horas por dia até desidratação total durante um período de quatro dias (Figura 2).

Para a composição do substrato, foi coletado solo no Campus experimental da Fundação Universidade Federal de Rondônia - UNIR, localizado no Km 15 sentido Norte. Na sequência, esse solo foi peneirado em malha de 4,0 milímetros e armazenado em sacos de polietileno e transportado até as instalações do REProFlor. O solo foi classificado como latossolo vermelho-amarelo distrófico e apresentou as seguintes características químicas: potencial hidrogeniônico em água $\left(\mathrm{pH} \mathrm{em} \mathrm{H}_{2} \mathrm{O}\right)=6,44$; Matéria Orgânica

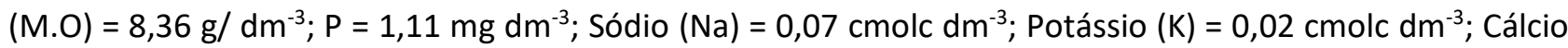
(Ca) = 0,88 $\mathrm{cmolc} \mathrm{dm}^{-3}$; Magnésio $(\mathrm{Mg})=0,64 \mathrm{cmolc} \mathrm{dm}^{-3}$; Alumínio $(\mathrm{Al})=0,00 \mathrm{cmolc} \mathrm{dm}^{-3}$; Hidrogênio + Alumínio $(H+A l)=3,63 \mathrm{cmolc} \mathrm{dm}^{-3} ;$ Argila $=21,0 \%$; Areia $=43,88 \%$.

Também foi coletada areia para a composição do substrato, esta foi peneirada para retirar as impurezas e descartada a parte mais fina; permanecendo somente a parte mais grossa, que foi lavada e solarizada em lona por sete dias, sendo revolvida diariamente.

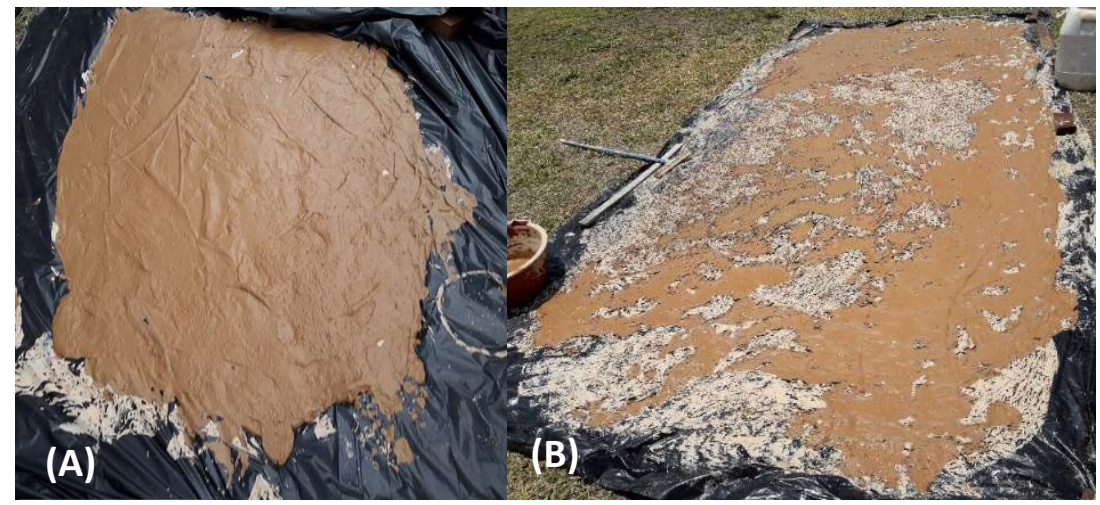




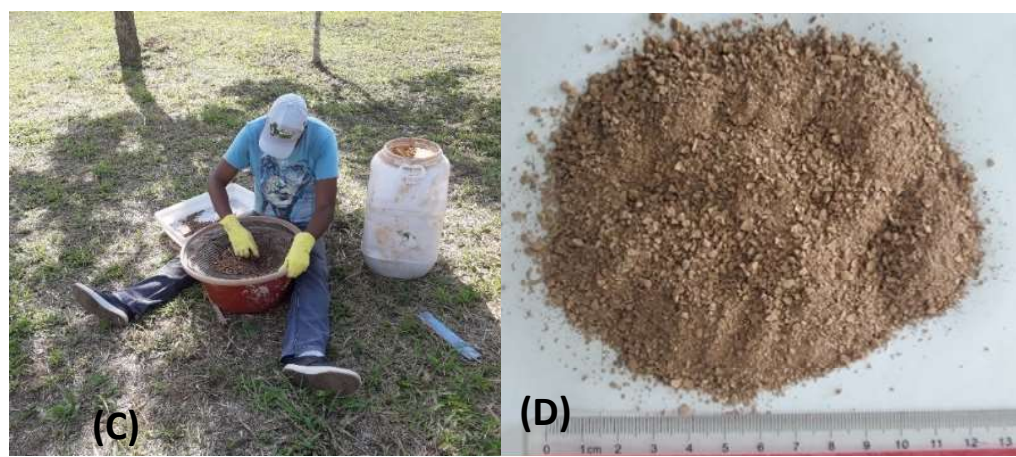

Figura 2: Preparo do lodo de Estação de Tratamento de Água (ETA): A) Lodo de ETA úmido sendo secado ao sol; B) Lodo de ETA parcialmente seco; C) Lodo de ETA sendo peneirado em malha de $4 \mathrm{~mm}$; e D) Lodo de ETA totalmente seco, triturado e pronto para o uso. Rolim de Moura-RO.

Foi utilizado uma espécie florestal nativa (Handroathus impetiginosus (Mart. ex DC) Mattos) e uma exótica (Eucalyptus camaldulensis Dehnh). As sementes de H. Impetiginosus foram coletadas em 2018, de matrizes localizadas zona urbana do município de Rolim de Moura (Figura 3). Os lotes foram acondicionados em envelopes de papel e armazenados em sacos plásticos transparente, sob refrigeração de $80 \mathrm{C}$. $\mathrm{E}$ as sementes de eucalipto foram adquiridas comercialmente (Cultivar LCFA 014, safra 2017, lote 152, com 95\% de germinação, $95 \%$ de viabilidade, $99 \%$ de pureza).

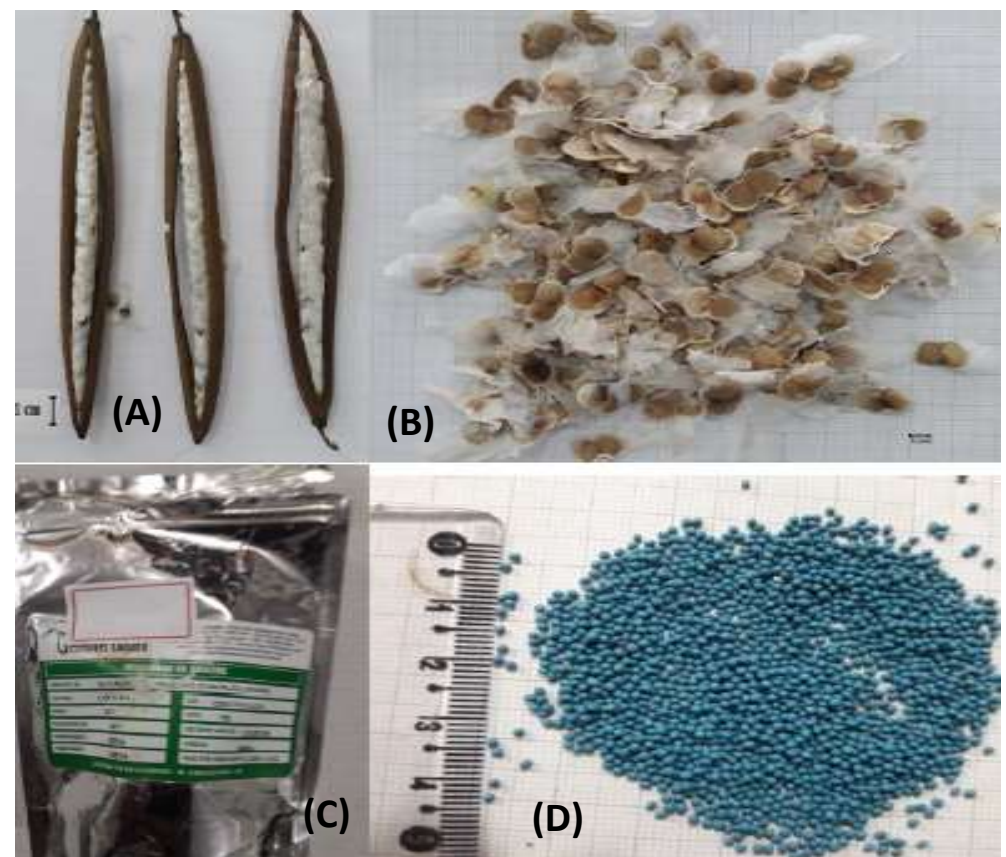

Figura 3: Sementes utilizadas para realização do experimento (A) Fruto maduro de Handroathus impetiginosus (Mart. ex DC) Mattos; (B) sementes de H. impetiginosus de um lote, coletados em fragmentos florestais da zona da mata rondoniense; (C) e (D) Lote de sementes de Eucalyptus camaldulensis Dehnh utilizadas para o experimento, adquirida comercialmente, Rolim de Moura, RO.

Os tratamentos avaliados foram compostos por lodo de ETA, solo e areia grossa em diferentes proporções: T1 - Testemunha, $50 \%$ areia grossa $+50 \%$ de solo; $\mathrm{T} 2-15 \%$ de lodo de ETA $+42,5 \%$ de areia grossa $+42,5 \%$ de solo; T3 $-30 \%$ de lodo de ETA $+35 \%$ de areia grossa $+35 \%$ de solo; $\mathrm{T} 4-45 \%$ de lodo de ETA $+27,5 \%$ de areia grossa $+27,5 \%$ de solo; $T 5-60 \%$ de lodo de ETA $+20 \%$ de areia grossa $+20 \%$ de solo

Os substratos compostos foram acomodados em bandejas de polietileno $(55 \mathrm{~cm} \times 34 \mathrm{~cm} \times 15 \mathrm{~cm})$ drenadas. As bandejas foram instaladas em bancadas no viveiro, sendo que cada bandeja foi dividida em 
quatro blocos. O delineamento experimental utilizado foi blocos casualizados, com cinco tratamentos e quatro repetições. Cada repetição foi composta por 26 sementes, resultando 112 sementes por tratamento, totalizando 448 sementes de cada espécie. Todas as bandejas foram irrigadas manualmente no período da manhã e à tarde durante todo o tempo do experimento.

Diariamente foi quantificada a porcentagem de germinação das sementes, sendo que foram consideradas germinadas as plântulas que emitiram dois cotilédones normais. O índice de velocidade de germinação (IVG) foi calculado de acordo com está fórmula:

$$
\mathrm{IVG}=\mathrm{N} 1 / \mathrm{D} 1+\mathrm{N} 2 / \mathrm{D} 2+\ldots+\mathrm{Nn} / \mathrm{Dn}
$$

em que: $\mathrm{G} 1, \mathrm{G} 2, \ldots, \mathrm{Gn}$ = número de plântulas germinadas na primeira, segunda, até a última contagem; N1, N2, ..., Nn = número de dias desde a primeira, segunda, até a última contagem.

O tempo médio de germinação (TMG) foi determinado de acordo com está equação:

$$
T M G=\frac{\sum n_{i} * t_{i}}{\sum n_{i}}
$$

em que: $\mathrm{n}_{\mathrm{i}}=$ número de plântulas desde a primeira, segunda, até a última contagem; $\mathrm{t}_{\mathrm{i}}=$ tempo após instalação do experimento e i = 1 em 1 dia até a estabilização da germinação das sementes: 30 dias.

A Velocidade média de germinação (VMG) foi calculada pela fórmula:

$$
V M G=\frac{1}{T M G}
$$

em que: TMG = tempo médio de germinação em unidade: dias $^{-1}$.

Após a tabulação, os dados, foram submetidos ao teste de normalidade de Shapiro-Wilk a 5\% de significância e à modificação do teste de Levene a 5\% de significância. Na sequência, foi submetido ao modelo de variância de um delineamento de blocos casualizados $(P \geq 0,95)$ e, no caso de constatadas diferenças significativas, ao teste de Tukey ( $P \geq 0,95)$. Os dados foram analisados no software $R$ ( $R$ Core Team, 2018), através do pacote ExpDes.pt (FERREIRA et al., 2009).

\section{RESULTADOS E DISCUSSÃO}

Por meio da caracterização físico-química deste lodo de ETA foi detectado a presença de alguns macronutrientes ( $\mathrm{Ca}, \mathrm{P}, \mathrm{Mg}$ e $\mathrm{K})$, em concentrações consideráveis e uma menor quantidade de micronutrientes (Bo, Co, $\mathrm{Mn}$ e $\mathrm{Ni}$ ), além de alta concentração de matéria orgânica (Tabela 1). E dentre os atributos avaliados, apenas os elementos químicos alumínio e manganês extrapolaram os valores máximos permitidos pelas Resoluções no. 357/2006 e 430/2011, visto que estas legislações não preveem valores máximos para os macronutrientes encontrados na amostra.

Tabela 1 Parâmetros físico-químicos de massa seca analisados em amostra de Lodo de Estação de Tratamento de Água disponibilizado pela empresa Companhia de Água e Esgoto de Rondônia, município de Porto Velho, coletado em outubro de 2018.

\begin{tabular}{|l|l|l|l|l|}
\hline \multicolumn{1}{|c|}{ Parâmetros físico-químicos } & \multicolumn{1}{c|}{ Unidade } & \multicolumn{1}{c|}{ LQ } & \multicolumn{1}{c|}{ Resultado } & 0,2 \\
\hline Al - Alumínio & $\mathrm{mg} \mathrm{dm}^{-3}$ & 0,005 & 0,402 & 0,5 \\
\hline As - Arsênio total & $\mathrm{mg} \mathrm{dm}^{-3}$ & 1,0 & $<0,005$ & 5,0 \\
\hline Bo - Boro total & $\mathrm{mg} \mathrm{dm}^{-3}$ & 5,881 & $<5,881$ & 0,5 \\
\hline Cd - Cadmio total & $\mathrm{mg} \mathrm{dm}^{-3}$ & 0,005 & $<0,003$ & \\
\hline Ca - Cálcio & $\mathrm{mg} \mathrm{dm}$ & 447,0 & 0,05 \\
\hline Co - Cobalto & $\mathrm{mg} \mathrm{dm}^{-3}$ & 58,810 & 3,360 & 0,2 \\
\hline Pb - Chumbo total & $\mathrm{mg} \mathrm{dm}^{-3}$ & 1,00 & $<0,005$ & 176 \\
\hline Fe - Ferro total & $\mathrm{mg} \mathrm{dm}^{-3}$ & 0,05 & 0,196 & \\
\hline
\end{tabular}




\begin{tabular}{|c|c|c|c|c|}
\hline Mn - Manganês & $\mathrm{mg} \mathrm{dm}^{-3}$ & 0,0005 & 4,687 & 1,0 \\
\hline Hg - Mercúrio Total & $\mathrm{mg} \mathrm{dm}^{-3}$ & 0,1 & $<0,0002$ & 0,001 \\
\hline Mg - Magnésio & $\mathrm{mg} \mathrm{dm}^{-3}$ & 58.810 & 519,0 & \\
\hline $\mathrm{Ni}$ - Níquel total & $\mathrm{mg} \mathrm{dm}^{-3}$ & 0,294 & 6,870 & 2,0 \\
\hline K - Potássio total & $\mathrm{mg} \mathrm{dm}^{-3}$ & 58,810 & 482,0 & \\
\hline Be - Berílio Total & $\mathrm{mg} \mathrm{dm}^{-3}$ & 0,176 & $<0,176$ & 0,7 \\
\hline Li - Lítio total & $\mathrm{mg} \mathrm{dm}^{-3}$ & 0,294 & 19,2 & 2,5 \\
\hline$P$ - Fósforo total & $\mathrm{mg} \mathrm{dm}^{-3}$ & 2,94 & 580,0 & \\
\hline Se - Selênio total & $\mathrm{mg} \mathrm{dm}^{-3}$ & 0,01 & $<0,005$ & 0,3 \\
\hline $\mathrm{Na}$ - Sódio total & $\mathrm{mg} \mathrm{dm}^{-3}$ & 1,00 & 10,0 & \\
\hline Zn - Zinco & $\mathrm{mg} \mathrm{dm}^{-3}$ & 5,00 & 0,017 & 5,0 \\
\hline MO - Matéria Orgânica & $\%$ & 0,1 & 10,4 & - \\
\hline $\mathrm{pH}$ & - & $0-14$ & 4,62 & - \\
\hline
\end{tabular}

Legenda: LQ: Limite de Quantificação pelo analítico (equipamento); VMP: Valor Máximo Permitido com base na Resoluções no 357/2006 e Resolução no 430/2011 do Conselho Nacional do Meio Ambiente (CONAMA).

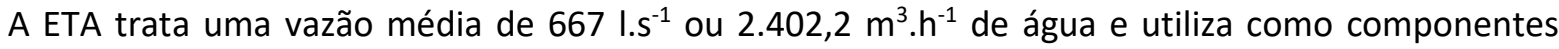
químicos para o tratamento da água o coagulante Sulfato de Alumínio $\left(\mathrm{Al}_{2}\left(\mathrm{SO}_{4}\right)_{3}\right)$, cal hidratada e cloro para desinfecção. Os processos físicos e químicos de tratamento de água consistem pelas fases de adução, floculação, decantação, filtragem e desinfecção, e destina o lodo gerado durante o tratamento no próprio rio Madeira.

Dentre os metais tóxicos encontrados na amostra, o alumínio foi o que apresentou maior expressividade. Porém, ressalta-se que os elementos ferro, cadmio, chumbo, mercúrio e selênio também são tóxicos quando em concentrações acima do valor máximo permitido pela resolução no. 430/2011 do CONAMA.

Esse resultado era esperado para o alumínio, devido ao tipo de coagulante utilizado pela ETA de Porto Velho ser o sulfato de alumínio. Este atributo é um dos principais limitantes no estabelecimento e desenvolvimento de plantas economicamente importantes em solos ácidos. Sendo que, a forma $\mathrm{Al}^{3+}$ é comprovadamente tóxica e o sintomas inicial é a inibição do crescimento da raiz, afetando desta forma o alongamento e a divisão celular que diminuem a capacidade da planta em obter água e nutrientes do solo (ECHART et al., 2001).

Isso ocorre porque o alumínio reduz a absorção e translocação de fósforo, cálcio e magnésio na planta, reduzindo consequentemente a produtividade da agricultura. A solubilidade do alumínio no solo e sua toxidez para as plantas depende de fatores como pH do solo, matéria orgânica e concentração de outros cátions. O alumínio é especialmente tóxico em qualquer concentração em solos com pH abaixo de 5,0, mas ainda pode causar danos quando o pH é até 5,5.

Com relação à concentração de macronutrientes, verificou-se que o lodo de ETA apresentou valores consideráveis, destacando-se o cálcio que apresentou valores acima de $400 \mathrm{mg} \cdot \mathrm{dm}^{-3}$, sendo considerados muito bom quando comparado com os valores de referência de Ribeiro et al. (1999). Sua função é atuar no crescimento global e desenvolvimento da planta, bem como no crescimento da raiz, desintoxicação dos íons de hidrogênio e divisão celular (TAIZ et al., 2004; SOBRAL et al., 2015; LIMA et al., 2016).

Verificou-se também valores importantes do fósforo total (19.727,9\% acima do limite quantificável). O fósforo pode contribuir para o crescimento da planta, além de desempenhar papel fundamental no metabolismo, fotossíntese, respiração e energia celular. Enquanto sua deficiência pode causar retardo de 
crescimento, podendo ser verificada na coloração púrpura das folhas mais velhas ou no caule das espécies florestai.

Os valores de $\mathrm{Mg}$ também foram importantes, visto que é um constituinte da clorofila e sua presença evita o amarelamento das nervuras foliar. O potássio desempenha diversas funções tais como: síntese de proteínas, desenvolvimento de raízes, produção de matéria seca atua no processo de fotossíntese e pode contribuir no equilíbrio das funções osmóticas (NASCIMENTO, 2014). Alguns autores consideram que as concentrações de $\mathrm{Ca}, \mathrm{P}, \mathrm{Mg}$ e $\mathrm{K}$ acima de $4,0 \mathrm{mg} \cdot \mathrm{dm}^{-3}, 45 \mathrm{mg} \cdot \mathrm{dm}^{-3}, 1,5 \mathrm{mg} \cdot \mathrm{dm}^{-3}$ e $120 \mathrm{mg} \cdot \mathrm{dm}^{-3}$, respectivamente, são consideradas altas, semelhantes às encontradas no lodo da ETA analisado.

Embora os macronutrientes sejam relevantes para o crescimento das plantas, o excesso de alguns deles podem causar antagonismo ou competição entre cátions, principalmente entre o $\mathrm{Ca}, \mathrm{Mg}$ e $\circ \mathrm{K}$. Medeiros et al. (2008) avaliando o efeito de diferentes relações entre cálcio e magnésio observaram que elevadas concentrações de Ca trocável no solo pode diminuir a absorção de Mg e K pelas plantas, em função do antagonismo existentes entre estes atributos.

Os teores dos micronutrientes encontrados na amostra foram baixos, exceto o valor do Mn que foi acima valor permitido pela Resolução CONAMA 430/2011, contudo este elemento é essencial para o crescimento da planta, tanto que sais de manganês são adicionados aos fertilizantes onde há deficiência deste elemento no solo. Assim, deve-se destacar que as concentrações verificadas de manganês e níquel estão acima do valor máximo permitido pela Resolução CONAMA 430/2011, que estabelece valores máximos de $1,0 \mathrm{mg} \cdot \mathrm{Kg}^{-1}$ e $2,0 \mathrm{mg} \cdot \mathrm{Kg}^{-1}$ respectivamente. Os micronutrientes são exigidos em escalas menores aos macronutrientes, porém é relevante que o substrato contenha os elementos: ferro, manganês, zinco, cobre, boro, molibdênio e cloro.

A presença de lítio foi observada foi alta $\left(19,2 \mathrm{mg} \cdot \mathrm{Kg}^{-1}\right)$, sendo o valor observado acima de $2,5 \mathrm{mg} . \mathrm{Kg}$ ${ }^{1}$ conforme sugere a Resolução CONAMA №. 357/2005, o que pode ser tóxico para as plantas. A absorção deste metal pelas plantas está relacionada às do $\mathrm{Na}$ e $\mathrm{K}$, pois a presença destes cátions $\left(\mathrm{K}^{+}\right.$e $\left.\mathrm{Na}^{+}\right)$em alta concentração estabelece uma concorrência com o cátion Li, interferindo na absorção da planta (FAQUIN, 2005).

O lodo de ETA apresentou concentrações importantes de matéria orgânica que pode contribuir para a retenção de água no solo e aumentar o estoque de nutrientes e atividade biológica se misturado com o solo. E neste sentido, a matéria orgânica (MO) é considerada um bom indicador para a qualidade do substrato, visto que este fator é favorável para que a nutrição da planta seja eficiente. Esta concentração de matéria orgânica é formada a partir de uma multiplicidade de resíduos orgânicos, submetidos a uma serie de reações e ações de diversos organismos presentes na água, sendo constituída dos elementos químicos carbono, hidrogênio, oxigênio, enxofre e fósforo.

E por fim, o lodo apresentou baixo $\mathrm{pH}$, indicando acidez no resíduo e apresentou-se abaixo do valor mínimo para lançamento de efluente, conforme estabelece a Resolução CONAMA 430/2011. Este valor encontrado pode favorecer a toxidade do alumínio e dos demais metais presentes no lodo. Considerando que no rio Madeira ocorrem intensas atividades mineradoras, esperava-se que as concentrações de metais 
fossem mais elevadas. No entanto, estes valores abaixo dos limites de identificação pelo método utilizado podem estar relacionados à barreira formada pela Hidrelétrica de Santo Antônio que reduz o fluxo de sedimentos próximo ao ponto de captação de água, que ocorre abaixo da Hidrelétrica.

Porém, mesmo que as concentrações de metais tóxicos estejam abaixo dos limites de quantificação, o lodo proveniente do sistema de tratamento de água da Companhia de Água e Esgoto de Rondônia é definido como resíduo sólido, e a grande concentração de sólidos sedimentáveis presentes neste resíduo impedem o lançamento, sem prévio tratamento, do lodo produzido nas ETA's. Sendo assim, a utilização deste resíduo como substrato na produção de mudas pode ser uma forma adequada de destinação, uma vez que este resíduo é fonte de matéria orgânica para o solo e de macro e micronutrientes para o desenvolvimento das plantas. A germinação das sementes de $H$. impetiginosus estabilizou aos 21 dias e houve germinação em todos os tratamentos, variando de $14,29 \%$ a $90,2 \%$. As maiores porcentagens de germinação ocorreram nos tratamentos de maiores concentração de lodo de ETA (Figura 4).

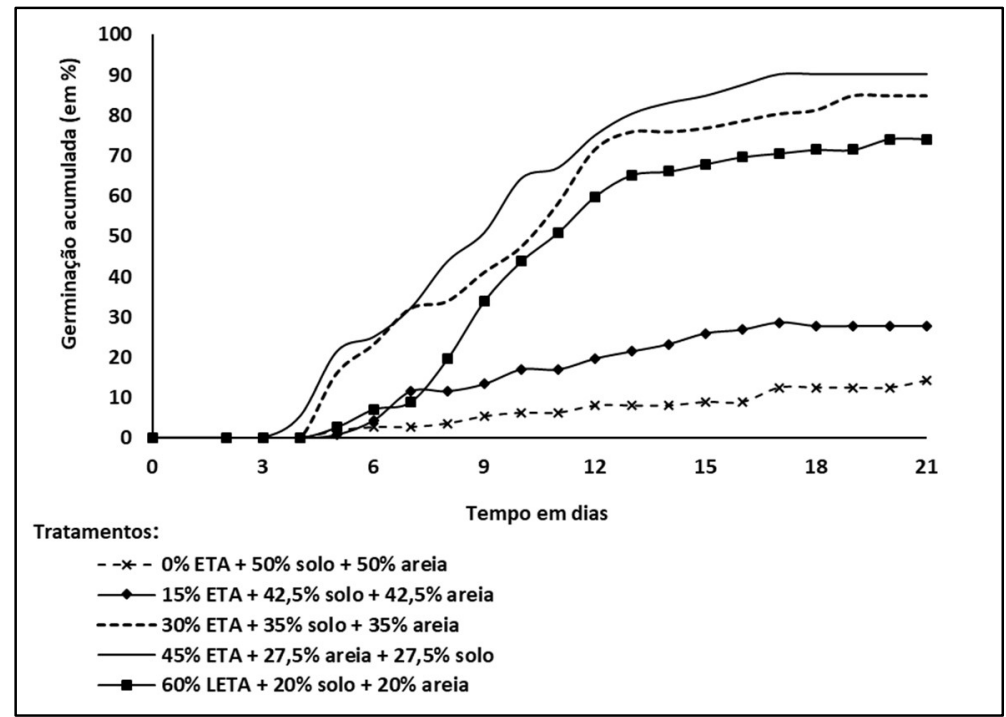

Figura 4: Germinação acumulada (\%) de sementes Handroanthus impetiginosus (Mart. Ex) Mattos coletadas em outubro de 2018 na zona da mata rondoniense, semeadas em diferentes composições de substratos em casa de vegetação, em função do tempo (dias). Legenda: ETA: lodo de Estação de Tratamento de Água.

A utilização do lodo de ETA como substrato foi importante para germinação de sementes de $H$. impetiginosus, visto que os resultados finais foram considerados elevados em relação à porcentagem de $40 \%$ de germinação sugeridos por Lorenzi (2003). Deve-se ressaltar que o lodo pode ter influenciado diretamente na germinação em função da sua estrutura, aeração e capacidade de retenção hídrica. Esta adequação da disponibilidade de água dos substratos associados à qualidade das sementes utilizadas, garante a germinação das sementes e posterior emergência das plântulas (GRAVE et al., 2007).

Assim, para atributo de fertilidade, aos 30 dias foram verificadas diferenças entre a testemunha e cada um dos tratamentos com concentrações crescentes de lodo de ETA, demonstrando que o resíduo alterou as características do solo e areia favorecendo a germinação da plântula. Em contraponto à germinação de $H$. impetiginosus, a germinação das sementes de $E$. camaldulensis se apresentaram com maior viabilidade no tratamento testemunha e menor porcentagem na maior concentração de lodo de ETA, com percentuais variando de $10,71 \%$ a $43,75 \%$ (Figura 5 ). 
Esses percentuais são considerados baixos quando comparados com os encontrados por Centinarsk Filho et al. (2009), que alcançaram $80 \%$ de germinação em substrato e areia pura à temperatura de 30 으. Porém, considerando que o objetivo do trabalho foi avaliar as potencialidades do lodo de ETA e sugerir uma alternativa ambientalmente correta, o tratamento com 30\% de lodo teve maior expressividade na porcentagem de germinação na utilização deste resíduo incorporado ao substrato.

Isto corrobora com Rocha et al. (2015), que salientam que o lodo de ETA como parte do composto de substrato na produção de mudas de $E$. urograndis é viável do ponto de vista técnico, econômico e ambiental em concentrações até 50\%, tornando-se assim uma alternativa para utilização desse resíduo, o que evitaria sua deposição nos cursos d'água.

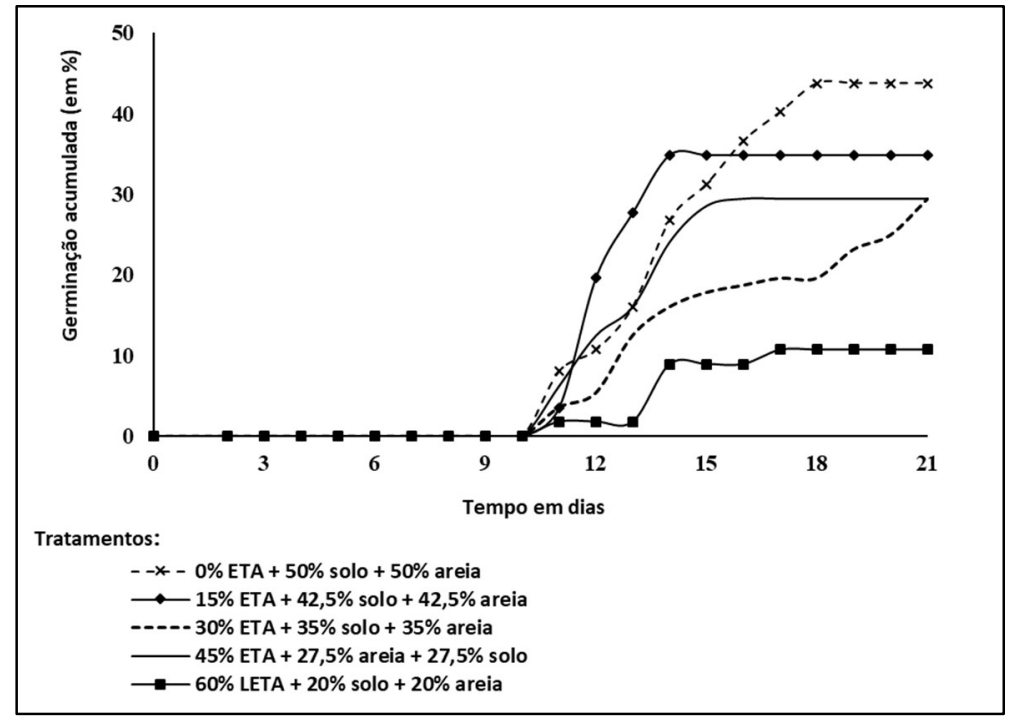

Figura 5: Germinação acumulada (\%) de sementes Eucalyptus camaldulensis Dehnh adquirido comercialmente, semeadas em diferentes composições de substratos em casa de vegetação, em função do tempo (dias). Legenda: ETA: lodo de Estação de Tratamento de Água.

O baixo $\mathrm{pH}$ do lodo de ETA pode ter sido um dos fatores que influenciaram na baixa germinação do E. camaldulensis, principalmente quando este atributo é associado à presença de metais no substrato. Durante a embebidação da semente, é provável que estes metais tenham afetado o crescimento da plântula inibindo a emergência da mesma.

A germinação de sementes é uma das fases críticas para o estabelecimento das plantas em condições naturais. De maneira fisiológica, a germinação inicia com a embebidação de água pela semente, seguida da retomada do crescimento do embrião quiescente e terminando com a protrusão de alguma parte deste por meio do tegumento (SILVA et al., 2018).

De maneira geral, a porcentagem de germinação indica a proporção total de sementes germinadas, entretanto não reflete quanto tempo foi necessário para que as sementes atingissem tal porcentagem de germinação. Ou seja, se dois ou mais lotes apresentam germinabilidade de semente, isso não quer dizer que o comportamento germinativo seja o mesmo (BORGHETTI et al., 2004).

Então, para atributo de germinação foram verificadas diferenças significativas entre a testemunha e cada um dos tratamentos com concentrações crescentes de lodo de ETA, demonstrando que o resíduo 
alterou as características do solo e areia. O que pode ter favorecido a germinação da plântula, no caso do $H$. impetiginosus (Figura 1) e inibido germinação acumulada (\%) de sementes E. camaldulensis.

Sendo assim, as sementes de $H$. impetiginosus possuem rápida germinação, conforme verificado pelo Índice de Velocidade de Germinação (IVG), Tempo Médio de Germinação (TMG) e Velocidade Média de Germinação (VMG), enquanto a espécie E. camaldulensis teve redução de valores destes parâmetros à medida que a concentração de lodo aumentou (Tabela 2).

Tabela 2: Índice de velocidade de germinação (IVG) e tempo médio (TMG) e velocidade média (VMG) de germinação de sementes Handroanthus impetiginosus (Mart. Ex) Mattos coletadas em outubro de 2018 na zona da mata rondoniense e Eucalyptus camaldulensis Dehnh adquirida comercialmente e semeadas em diferentes concentrações de Lodo de ETA em casa de vegetação. Rolim de Moura/RO.

\begin{tabular}{|c|c|c|c|c|c|c|}
\hline \multicolumn{4}{|c|}{ Handroanthus impetiginosus (Mart. Ex) Mattos } & \multicolumn{3}{|c|}{ Eucalyptus camaldulensis Dehnh } \\
\hline Tratamentos & IVG & TMG & VMG & IVG & TMG & VMG \\
\hline & & (dias) & $\left(\right.$ sementes.dia $\left.{ }^{-1}\right)$ & & (dias) & (sementes.dia ${ }^{-1}$ ) \\
\hline T1 & $4,00^{d}$ & $5,92^{d}$ & $0,169^{d}$ & $20,85^{a}$ & $4.09^{a}$ & $0.244^{a}$ \\
\hline $\mathrm{T} 2$ & $11,31^{\mathrm{cd}}$ & $5,16^{\mathrm{cd}}$ & $0,194^{\text {cd }}$ & $7,63^{\mathrm{b}}$ & $4,85^{b}$ & $0,206^{b}$ \\
\hline T3 & $32,94^{\mathrm{ab}}$ & $4,48^{\mathrm{ab}}$ & $0,197^{a b}$ & $8,47^{\mathrm{b}}$ & $8.39^{b}$ & $0.119^{b}$ \\
\hline $\mathrm{T} 4$ & $42,15^{a}$ & $4,40^{a}$ & $0,227^{a}$ & $9,32^{b}$ & $4,72^{b}$ & $0,212^{b}$ \\
\hline T5 & $20,25^{b c}$ & $5,88^{b c}$ & $0,170^{b c}$ & $4,43^{b}$ & $5,73^{b}$ & $0,174^{b}$ \\
\hline
\end{tabular}

Legenda: Médias seguidas de mesma letra na linha não diferem entre si ao nível de $5 \%$ de probabilidade de erro pelo teste de Tukey. Legenda: ETA- Estação de Tratamento de Água; T1 (50\% solo + 50\% areia); T2 (15\% Lodo + 42,5\% solo + $42,5 \%$ areia); T3 (30\% lodo + 35\% solo + 35\% areia); T4 (45\% lodo + $27,5 \%$ solo $+27,5 \%$ areia); e T5: (60\% lodo + $20 \%$ solo $+20 \%$ areia).

O IVG da espécie $H$. impetiginosus não sofreu efeito inibitório, porém entre os tratamentos houve diferença significativa, em destaque os tratamentos de maiores concentrações de lodo de ETA. Esse resultado confirma a melhor viabilidade para o tratamento 4 ( $45 \%$ de lodo de ETA), que apresentou melhor valor para este parâmetro. Outros estudos também apontam que a concentração de $45 \%$ é viável para produção de mudas, pois encontraram valores semelhantes para o gênero Handroanthus. É provável também que o resultado encontrado esteja relacionado ao fornecimento de outros nutrientes advindos do lodo que não foram detectados. Dentre eles o nitrogênio que se torna disponível pela mineralização do lodo promovida por microrganismos durante o processo de germinação.

Por meio do teste de Levene, $p$-valor 0,2755 a 5\% de significância, as variâncias dos índices de germinação podem ser consideradas homogêneas; e por meio no teste de Shapiro-Wilk a 5\% de significância, p-valor 0,7412631, os resíduos podem ser considerados normais. E na aplicação do teste Tukey ao nível de $5 \%$ de probabilidade, foi observada diferença significativa entre os tratamentos na germinação de $H$. impetiginosus, sendo o tratamento com $45 \%$ de lodo de ETA o que apresentou melhor resultado.

Ainda avaliando a espécie $H$. impetiginosus, os parâmetros TMG e VMG foram fundamentais para confirmar que o tratamento 4 apresentou o menor tempo necessário para germinação das sementes utilizadas e maior velocidade de germinação em relação aos demais. Os melhores resultados tendem a acompanhar as crescentes concentrações de lodo, embora o tratamento 2 foi relevante nos quesitos TMG e VMG, mesmo não estando entre os de maior porcentagem de germinação.

Já os valores encontrados nos tratamentos para a espécie $E$. camaldulensis foram baixos na presença do lodo de ETA, sendo que a testemunha apresentou o melhor IVG comparado aos demais tratamentos, e 
também em relação aos valores encontrados para a espécie $H$. impetiginosus. Os valores de IVG foram submetidos ao teste de Levene, apresentando $p$-valor 0,0602 a 5\% de significância, as variâncias do índice de germinação podem ser consideradas homogêneas e com base no teste de Shapiro-Wilk a 5\% de significância, p-valor 0,0766, os resíduos podem ser considerados normais. Por meio de aplicação do teste Tukey, ao nível de $5 \%$ de probabilidade, na germinação de sementes de $E$. camaldulensis foi observada diferença significativa entre os tratamentos, e a testemunha apresentou os melhores valores quando comparada com os demais tratamentos.

O TMG corresponde à média do tempo necessário para um conjunto de semente germinar, dando ao processo um caráter cinético, de modo que quanto menor for o valor do tempo de germinação, maior será a eficiência das sementes e o maior valor encontrado foi no tratamento 3, indicando retardo na germinação do E. camaldulensis. A velocidade de germinação pode ser utilizada para identificar lotes com emergência mais rápida em campo ou em estufa, minimizando assim as condições adversas que ocorrem durante a germinação e estabelecimento de plântulas.

Após 40 dias de semeadura, foram observadas alterações na cor das folhas de $H$. impetiginosus, apresentando coloração púrpura nas folhas e nas nervuras em grande parte das mudas do tratamento T5 (60\% de lodo de ETA). Esta alteração é característica da deficiência de fósforo, porém Ferreira et al. (2006) e Conceição et al. (2008) salientam que os sintomas foliares de plantas na presença de alumínio se assemelham à deficiência de fósforo (folhas de crescimento anormal; coloração púrpura nos colmos, nas folhas e nas nervuras) ou a deficiência de cálcio, cuja causa é, enrolamento das folhas jovens, colapso no ápice da planta e dos pecíolos.

Estes sintomas também foram detectados na espécie de E. camaldulensis, em todos os tratamentos com concentração de lodo de ETA, porém os efeitos foram menores do que no tratamento 5 ( $45 \%$ de lodo) da espécie de $H$. impetiginosus. Outro aspecto observado foi o crescimento retardado destas mudas em relação às demais. Esta inibição de crescimento afeta o alongamento e a divisão celular desta estrutura, diminuindo a capacidade da planta para obter água e nutriente do subsolo, em virtude do enraizamento superficial, tornando-a menos produtiva e mais susceptível aos efeitos da seca (FERREIRA et al., 2006).

Por fim, as concentrações de lodo de ETA contribuíram para o crescimento da espécie de $H$. impetiginosus e pode ser considerada como alternativa ecologicamente adequada; além de ter sido um produto de baixo risco de contaminação ambiental para o solo, visto que as concentrações dos metais tóxicos verificados estão abaixo dos valores de quantificação permitidos pelas Resoluções do CONAMA. As quantidades de macronutrientes e matéria orgânica encontrada no lodo de ETA foram consideradas relevantes e pode contribuir na germinação e crescimento de mudas se for utilizada nas concentrações adequadas.

\section{CONCLUSÕES}

O lodo de ETA se mostra rico em macro e micronutrientes e matéria orgânica e pode ser utilizado na germinação de sementes devido a boa capacidade de aeração e absorção de água. A espécie $H$. impetiginosus 
pode ser germinada em substrato contendo $45 \%$ de lodo de ETA. Enquanto plântulas de E. camaldulensis apresentam toxidez quando germinadas em lodo de ETA, mas pode germinar com concentrações de 15\% de lodo de ETA acrescido ao substrato, apresenta 34,82\% de germinação. As concentrações recomendadas para germinação de $H$. impetiginosus variam de 30 a $60 \%$, sendo ótima na concentração $45 \%$. E para a espécie $E$. camaldulensis, a melhor porcentagem de germinação na presença do lodo de ETA foi no tratamento com $15 \%$, e nos demais parâmetros foi o tratamento 4 , com $30 \%$.

\section{REFERÊNCIAS}

APHA. American Public Health Association. Standard Methods for the Examination of Water and Wastewater. 19 ed. Washington: APHA, 2017.

CONAMA. Conselho Nacional Do Meio Ambiente. Resolução n. 430, 13 de maio de 2011. Dispõe sobre as condições e padrões de lançamento de efluentes, complementa e altera a Resolução n. 357, de 17 de março de 2005, do Conselho Nacional do Meio Ambiente - CONAMA. Brasília: DOU, 2011.

BRASIL. Lei n. 12.305 de 02 de agosto de 2010. Política Nacional de Resíduos Sólidos. Brasília: DOU, 2010.

BRASIL. Ministério do Meio Ambiente. Taxa de Desmatamento na Amazônia Legal. Brasília: MMA, 2018a.

BRASIL. Secretaria de Estado da Fazenda. Seção IX: madeiras, carvão vegetal e obras de madeira; cortiça e suas obras; obras de espartaria ou de cestaria. Brasília: SEFAZ, $2018 b$.

BORGHETTI, F.; FERREIRA, A. G.. Interpretação de resultados de germinação. In: Germinação: do básico ao aplicado. Porto Alegre: Artmed, 2004. p.209-222.

CAMPOS FILHO, E. M.; SARTORELLI, P. A. R.. Guia de árvores com valor econômico. São Paulo: Agroicone, 2015.

CETNARSKI FILHO, R.; CARVALHO, R. I. N.. Massa da amostra, substrato e temperatura para teste de germinação de sementes de Eucalyptus dunnii Maiden. Ciência Florestal, v.19, n.3, p.257-265, 2009.

CONCEIÇÃO, L. D. C. S.; SERENO, M. J. C. M.; NETO, J. F. B.. Tolerância Ao Alumínio Em Plantas: Toxicidade, Mecanismos E Genes Em Espécies Cultivadas. Agrociência, Pelotas, v.14, p.1-10, 2008.

ECHART, C. L.; CAVALLI-MOLINA, S.. Fitotoxicidade do alumínio: efeitos, mecanismo de tolerância e seu controle genético. Ciência Rural, v.31, n.3, p.531-541, 2001.

FAQUIM, V.. Mineral de Planas. Monografia (Especialização em Solos e Meio Ambiente) - Universidade Federal de Lavras, Lavras, 2005.

FERREIRA, E. B.; CAVALCANTI, P. P.; NOGUEIRA, D. A.. Função em código $R$ para analisar experimentos em DQL simples, em uma só rodada. In: CONGRESSO DE POS-GRADUACAO DA UNIVERSIDADE FEDERAL DE LAVRAS, 18. Anais. Lavras: UFLA, 2009.
FERREIRA, R. P.; MOREIRA, A.; RASSINI, J. B.. Toxidez de alumínio em culturas anuais. Brasília: Embrapa Pecuária Sudeste-Documentos, 2006.

GRAVE, F.; FRANCO, E. T. H.; PACHECO, J. P.; SANTOS, S. R.. Crescimento de plantas jovens de açoita-cavalo em quatro diferentes substratos. Ciência Florestal, Santa Maria, v.17, n.4, p.289-298, 2007.

INPE. Instituto Nacional de Pesquisas Especiais.

Desmatamento da Amazônia Legal. São José dos Campos: PRODES, 2017.

LIMA, Â. S. F.; CANTARELLI, M. M. C.; GONÇALVES, A. N. relação entre cálcio e temperatura em explantes de eucalyptus grandisin vitro. Nucleus, v.13, n.1, p.123-130, 2016.

LORENZI, H.; SOUZA, H. M.; TORRES, M. A. V.; BACHER, L. B.. Árvores exóticas no Brasil: madeiras ornamentais e exóticas. Nova Odessa: Instituto Plantarum, 2003.

MACHADO, L.; PEREIRA, J. A. R.; PONTE, M. X.; LOPES, L. D. N. A.. Avaliação do aproveitamento agrícola do lodo produzido na ETA Bolonha-RMB. In: CONGRESSO BRASILEIRO DE CIÊNCIA E TECNOLOGIA EM RESÍDUOS E DESENVOLVIMENTO SUSTENTÁVEL. Anais. 2004. p.917-926.

MEDEIROS, J. C.; ALBUQUERQUE, J. A.; MAFRA, A. L.; ROSA, J. D.; GATIBONI, L. C.. Relação cálcio: magnésio do corretivo da acidez do solo na nutrição e no desenvolvimento inicial de plantas de milho em um Cambissolo Húmico Álico. Semina: Ciências Agrárias, v.29, n.4, p.799-806, 2008.

NASCIMENTO, M. H.. Assimilação de lítio, sódio e potássio por plantas de alface. Dissertação (Mestrado em Solos e Qualidade de Ecossistemas) - Universidade Federal Recôncavo da Bahia, Cruz das Almas, 2014.

PRADO, A. D. L.; ROCHA, G. T.; MELO, B. S.; RODRIGUES, F.. Germinação de Sementes de Diferentes Espécies de Eucalipto sob Estresse Hídrico Simulado por Manitol. In: CONGRESSO DE ENSINO, PESQUISA E EXTENSÃO DA UEG. Anais. Goiânia: UEG, 2017.

ROCHA, D. N.; SOUZA, A. E.; QUEIROZ, L. M.; PONTES, C. A.. Utilização do lodo da estação de tratamento de água na produção de mudas de eucalipto. Revista

Agrogeoambiental, Pouso Alegre, v.7, n.3, p.11-20, 2015.

ROCHA, K. J.. Germinação de ipê-amarelo (Handroanthus serratifolius (Vahl) S.O.Grose) utilizando biossólido como componente de substrato. Monografia (Especialização em 
Gestão Ambiental) - Universidade Federal do Paraná, Curitiba, 2018.

SILVA, B. E. C.; PIMENTA, P. C. B.; JOLOMBA, M. R.; LUIZ, P. H. D.; POLONI, C. M. M.. Avaliação da germinação de sementes de ipê amarelo (Tabebuia chrysotricha (Mart. ex DC.) Standl.) em diferentes substratos. The Journal of Engineeringand Exact Sciences, v.4, n.3, p.0334-0337, 2018.

SOBRAL, L. F.; BARRETO, M. C. V.; SILVA, A. J.; ANJOS, J. L. Guia prático para interpretação de resultados de análises de solos. Brasília: Embrapa Tabuleiros Costeiros, 2015.
TAIZ, L.; ZEIGER, E.. Fisiologia vegetal. 3. ed. Porto Alegre: Artmed, 2004.

TSUTUYA, M. T.; HIRATA, A. Y.. Aproveitamento e Disposição Final de Lodos de Estação de Tratamento de Água do Estado de São Paulo. In: CONGRESSO BRASILEIRO DE ENGENHARIA SANITÁRIA E AMBIENTAL, 21. Anais. João Pessoa: ABES, 2001.

A CBPC - Companhia Brasileira de Produção Científica (CNPJ: 11.221.422/0001-03) detém os direitos materiais desta publicação. Os direitos referem-se à publicação do trabalho em qualquer parte do mundo, incluindo os direitos às renovações, expansões e disseminações da contribuição, bem como outros direitos subsidiários. Todos os trabalhos publicados eletronicamente poderão posteriormente ser publicados em coletâneas impressas sob coordenação da Sustenere Publishing, da Companhia Brasileira de Produção Científica e seus parceiros autorizados. Os (as) autores (as) preservam os direitos autorais, mas não têm permissão para a publicação da contribuição em outro meio, impresso ou digital, em português ou em tradução. 